Technological University Dublin

DƯBLIN

ARROW@TU Dublin

\title{
The Challenge of Educating Engineers for a Close, Crowded and Creative World
}

\author{
Ela Krawczyk \\ Mike Murphy \\ Technological University Dublin, mike.murphy@tudublin.ie
}

Follow this and additional works at: https://arrow.tudublin.ie/engineducbks

Part of the Engineering Education Commons

\section{Recommended Citation}

Krawczyk E., Murphy M. (2012). The Challenge of Educating Engineers for a Close, Crowded and Creative World. In: Christensen S., Mitcham C., Li B., An Y. (eds) Engineering, Development and

Philosophy:Philosophy of Engineering and Technology, vol 11. Springer. doi:10.21427/vd72-h873

This Book Chapter is brought to you for free and open access by the Engineering: Education and Innovation at ARROW@TU Dublin. It has been accepted for inclusion in Books/Book chapters by an authorized administrator of ARROW@TU Dublin. For more information, please contact arrow.admin@tudublin.ie, aisling.coyne@tudublin.ie, gerard.connolly@tudublin.ie.

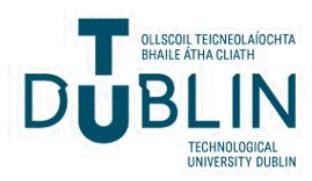


This article is a near-last version of a chapter that has been published as: Krawczyk E., Murphy M. (2012) The Challenge of Educating Engineers for a Close, Crowded and Creative World. In: Christensen S., Mitcham C., Li B., An Y. (eds) Engineering, Development and Philosophy. Philosophy of Engineering and Technology, vol 11. Springer, Dordrecht.

\title{
The Challenge of Educating Engineers for a Close, Crowded and Creative World
}

\author{
Ela Krawczyk and Mike Murphy
}

\begin{abstract}
The world that is emerging based on the development and everyday use of new technologies is a world that can be described as close, crowded and creative. Studies have highlighted that traditional curricula and pedagogical methods for engineering education are deficient in terms of developing and nurturing key skills required by engineers to succeed in this world. The challenge for the engineering academic leaders of today is to begin with the end in mind: to begin with a description of the competences that the engineer of the future should have in order to succeed in their aspirations as an engineer, and then to reverse engineer both the curriculum and pedagogical approaches to enable the desired outcome. This chapter describes what is meant by a close, crowded and creative world: the world in which engineering graduates must learn to practice. It then proposes three different possible scenarios for the world of 2030 and discusses the key skills that engineers in 2030 should possess in order to succeed as engineers. The chapter concludes with recommendations on how to address the challenges of educating engineers for a close, crowded and creative world.
\end{abstract}

Keywords: educating the engineer; engineering skills and competences; scenario planning; engineer 2030; 'close, crowded and creative world'

\section{Tomorrow's World Today}

What world are we living in today and what will the world look like that our children will live in tomorrow? In an award-winning book, Thomas Friedman describes the world of today as flat, by which he means that it is a world in which companies operate globally on a level playing field and wherein the development and application of technology shrink both time and distance (Friedman 2006). It is a world in which the continued development and application of technology leads to revolutionary implications for countries, companies and the individual.

The US National Academy of Engineering (NAE) describes guiding principles that it sees as shaping the world in which the engineer will practice in 2020. From the perspective of our world today, these principles are evolutionary and as characterised by Friedman. In the world of 2020 
the pace of technological innovation will continue to be rapid, the world will be intensely globally interconnected; the population of individuals who are involved with or affected by technology will be increasingly diverse and multidisciplinary; social, cultural, political and economic forces will continue to shape and affect the success of technological innovation; the presence of technology in our everyday lives will be seamless, transparent, and more significant than ever.

(NAE 2004)

The flat world of Friedman and the NAE world of 2020 both represent a steady development of technological and societal trends: they describe today's world tomorrow. In this chapter we propose three different possible future worlds in 2030, some of which explore potential discontinuities in current trends. Each possibility is written as a scenario to describe what that world of 2030 might be like.

We begin by describing the general role and desired competences of the engineer today in 2011. We then adopt a scenario approach to describe three likely future scenarios for the world in 2030, which all have elements of a world that is close, crowded and creative. We describe the working environment in which the Engineer of 2030 will most likely be expected to perform for each of the three future scenarios. The competences which would likely predominate or be most necessary in order for the engineer to be successful as an engineer are also identified.

\section{The Engineer of 2011}

There is no single archetypal engineer, or pattern which universally describes what engineers are, in the world of 2011. Descriptions of engineers tend to focus on what engineers do rather than on the intrinsic characteristics of what makes someone an engineer. Engineers practice in many diverse disciplines and perform many diverse roles, even within those disciplines. There are also many people who have been educated as engineers but no longer work in engineering roles.

Engineering schools have traditionally educated engineers to function effectively in technical engineering roles. This is to say that the traditional educational model to educate an engineer in 2011 will focus on developing the ability to create and apply solutions to technical problems from a knowledge and understanding of mathematics and scientific principles. The development of other skills in an engineer - for example the ability to be innovative, to have well-developed communication skills, to function well in teams of diverse talent - has generally been seen of lesser importance within an engineering curriculum. The engineering educator may also view the development of these non-technical skills as belonging within the domain of the workforce, i.e., that it is while working as an engineer that the engineering graduate should develop such skills.

However, in recent years there is a growing awareness of the necessity to broaden the education of the engineer: that the traditional educational model is producing engineers for relatively narrow types of jobs that are disappearing within industry. This is not to say that engineering graduates are no longer in demand far from it, but rather the skills that employers wish them to have as they exit university with their engineering degree have evolved to include a range of non-technical skills. In an important publication in 2004 the US National Academy of Engineering asked the 
questions "should the engineering profession anticipate needed advances and prepare for a future where it will provide more benefit to humankind? Likewise, should engineering education evolve to do the same?" (NAE 2004). The NAE develops the case for "engineers who are broadly educated, see themselves as global citizens, can lead in business and public service, as well as in research, development and design, are ethical and inclusive of all segments of society". Evidence that change in engineering curricula must happen appears in the changing accreditation criteria for professional engineering degrees and in the literature, as described below.

\subsection{Attributes of the Engineer of 2011}

Let us briefly examine how engineers are educated today and what competences they are expected to possess as they graduate from university. Consider the accreditation criteria set by standards and professional bodies in the United States (ABET), the United Kingdom (Engineering Council) and in Ireland (Engineers Ireland). Accreditation criteria specify "what students are expected to know and be able to do by the time of graduation. These relate to the skills, knowledge, and behaviours that students acquire in their matriculation through the program" (ABET 2010). Accreditation criteria are generally mutually consistent for programmes leading to the educational standard required for professional engineering. The following paragraphs describe these composite skills.

Knowledge Skills - Engineering graduates must be able to demonstrate their knowledge and understanding of essential facts, concepts, theories and principles of their engineering discipline. They must be able to derive and apply solutions from a knowledge of sciences, technology and mathematics; and must have the ability to identify, formulate, analyse and solve engineering problems.

Intellectual Skills - Engineering graduates must be able to demonstrate creative and innovative ability in the synthesis of solutions and in formulating designs. They must have an ability to design a system, component, or process to meet desired needs within realistic constraints such as economic, environmental, social, political, ethical, health and safety, manufacturability, and sustainability.

Practical Skills - Engineering graduates must possess practical engineering skills including the ability to design and conduct experiments, as well as to analyze and interpret data. Thus the engineering graduate must be capable of using the techniques, skills and engineering tools necessary for engineering practice.

General transferable skills - Engineering graduates must possess the ability to work effectively as an individual, but also in teams and in multi-disciplinary settings. They must have the ability to communicate effectively, in writing and orally, both with the engineering community and with society at large. They should have the capacity to undertake lifelong learning. They should be capable of understanding the impact of engineering solutions in a global, economic, environmental, and societal context and they should understand the need for high ethical standards in the practice of engineering. (ABET 2010, EC 2006, EI 2007)

Essential Skills Reported by Irish Engineering Graduates and Employers

A recent research study conducted in Ireland of both engineering graduates and their employers validates the attributes described above. In this study over 8,000 recent engineering graduates (i.e., within 8 years of their graduation as engineers) from 81 different engineering programmes within Ireland were asked to participate in a survey and 1,496 of those graduates responded to the survey. Almost 400 organisations 
that employed those engineering graduates were surveyed and 74 employers responded. (IOT 2011)

The summary table 7.1 below lists the top ten skills that employers and engineering graduates reported as essential for engineers to succeed in the workplace. Each column is prioritized so, for employers, technical engineering skills were more important than written communication skills, etc.

Table 7.1 Prioritized list of Essential Engineering Skills

\begin{tabular}{|l|l|}
\hline \multicolumn{2}{|l|}{ Essential Engineering Skills } \\
\hline Prioritized List by Employers & Prioritized List by Graduates \\
\hline Technical Engineering & Critical/Analytical Thinking \\
\hline Written Communications & Oral Communications \\
\hline Teamwork & Teamwork \\
\hline Oral Communications & Interpersonal Skills \\
\hline Critical/Analytical Thinking & Written Communications \\
\hline Interpersonal Skills & Learning to learn \\
\hline IT/Software Skills & IT skills \\
\hline Creativity/Innovation skills & Management Skills \\
\hline Mathematical & Leadership \\
\hline Leadership & Creativity/Innovation \\
\hline
\end{tabular}

While employers place technical engineering competence top of their list, engineering graduates place it further down their list in $11^{\text {th }}$ position. That competence aside, the lists are remarkably similar and demonstrate that for both sets of people, general transferable skills such as critical thinking, communications, teamworking are considered essential for an engineering graduate to succeed.

\subsection{Attributes of the Engineer of 2020}

According to the NAE, the attributes of the Engineer of 2020 will be similar to those of today, but made more complex by the impacts of new technology. In addition to strong analytical skills, practical ingenuity and creativity will grow in importance. Engineers will require good communication skills, management and leadership skills. They will require a strong sense of professionalism and high ethical standards. The Engineer of 2020 will need to be dynamic, agile, resilient and flexible, and capable of lifelong learning. (NAE 2004)

\section{A Close, Crowded and Creative World}

During the first decade of the $21^{\text {st }}$ century we have observed profound changes brought about by advances in telecommunication and information technologies and globalisation. These changes do not simply affect how governments, businesses and people interact, but are paving the way towards the emergence of new social, political and business models. According to Friedman, one of the main consequences of these changes is a levelling of the global competitive field - the world becomes flat (2006). Besides being flat the present world can also be characterised as close, crowded and creative. 
The 'close' world is the world of disappearing barriers. With the absorption into everyday use of information and communication technologies distance, time and increasingly cultural differences cease being barriers in many areas of life: education, work, business, social interactions, medicine and others. In education, technology provides access to growing information sources, unlimited networks of people and computers and unprecedented learning and research opportunities (Wheeler 2001). Information technologies offer more opportunities for work and access to work, as work is no longer closely connected to geography and increasingly less to time zones. In business international corporations as well as small firms and individuals can conduct worldwide business instantaneously by searching for their trading partners online or producing and transmitting goods and services across the network (Spencer 2002).

As the world gets 'closer' it is also becoming more 'crowded' as competition for literally everything increases: jobs, market share, contracts, employees, students, projects, talent, expertise, funding, and, of course, natural resources. While in the past companies would compete against other firms similar in size and capability, in the 'close' world they operate in a much denser environment where they face not only their traditional competitors but also new and very different entrants to their field, such as large but flexible corporations and individual freelancers (Friedman 2006). Collaboration and co-opetition become important factors in a 'crowded' world characterised by interconnected economies. In the past, success in business could be characterised by market share and by "winner takes all" approaches, however, new business models are more nuanced and move away from pure competition towards recognition of the value of co-operative relationships that leverage value created within the network (Bowser 2011).

Of course, 'crowded' is a characteristic that applies beyond the business world. With the growing global population there are increased pressures on the world's natural resources, such as land, raw materials and water. These pressures are likely to continue to increase with the growth of middle classes all over the world and their aspirations to reach the standards of living enjoyed currently by developed economies. On the flip side, as prosperous societies "begin to produce enough food for people to leave the land, the excess labour gets trained and educated, it begins working in services and industry; that leads to innovation and better education and universities, freer markets, economic growth and development, better infrastructure, fewer diseases, and slower population growth" (Friedman 2006, p. 464). While additional millions of better educated and skilled people are likely to crowd the market even further, they will also bring new ideas and opportunities - making the world more creative.

As the world becomes more connected and crowded creativity and innovation become essential in dealing with the new challenges that emerge in such a world. Drucker (2001) has proclaimed that the next society will be a knowledge society, for which knowledge will be a key resource and knowledge workers will dominate the workforce. Education is the foundation of such a society. However, with almost everyone being able to access information and knowledge instantly using information technologies, the education programmes that will help people to succeed in today's world will need to equip them with knowledge and skills that will empower them to be creative and innovative in the way they use that knowledge and the technology available to them (Friedman 2006). These programmes will also need to 
develop leadership skills which will be especially important in times of technological determinism in the world where capabilities create intentions (Friedman 2006).

If the present driving forces of change continue to prevail in the future, then the world described above is likely to continue on its current development path. However, it is also possible that certain drivers may lose their importance, some significant trends today may discontinue tomorrow and new forces may emerge. In effect, quite different future worlds may develop. The roles and skills of the Engineer of 2030 may differ depending on what future emerges. To explore alternative future development paths we have used a scenario approach, which is discussed in detail in the next section.

\section{Scenario planning and global scenarios for 2030}

Scenarios are descriptions of plausible alternative futures that may emerge as a result of interactions between key drivers of change, trends and events. They are not predictions of the future but stories portraying different possible future outcomes (Krawczyk 2010). Usually, none of the scenarios come true but the actual future includes elements of different scenarios. Scenarios are used for ordering people's perceptions about alternative future environments in which decisions and plans made today may play out. Through a systematic identification and analysis of drivers, trends, issues and events scenario planning provides a better understanding of the dynamics of change and allows for consideration of a fuller range of opportunities and threats. By asking what if questions it helps to uncover the underlying, often hidden, assumptions about the future and expose the areas of risk and vulnerability (Ratcliffe 2009). Scenario planning is a widely recognised tool that assists us in making better decisions about the future today.

A scenario approach has been previously used to explore the future/ideal engineer of 2020 by the NAE (2004). The scenarios developed in the NAE project examined transformational changes that could emerge from breakthrough developments across several areas of technology, rapid advances in biotechnology, a major natural disaster and global divisions caused by religious fundamentalism. The scenario stories that resulted from the exercise focused on different aspects of technological development and its consequences for an engineer of 2020. The approach taken by the authors of this chapter aims to create a set of broad global scenarios that would depict the main drivers at play in a given future state as well as explore the broader work context for engineers in 2030.

There are many different sets of scenarios portraying the world in 2030. The majority of them assume globalisation, progress in science and technology, economy, sustainability and climate change, politics and population trends, to be the key forces that will intertwine and interact creating our future up to 2030. The scenarios developed for the purpose of this chapter and presented below are based on the scenario work carried out by The Futures Academy (Ratcliffe 2005, TFA 2008, Krawczyk \& Ronchetti 2009).

\section{Scenario 1: Orange (Liberty)}

This scenario assumes a continued globalisation, growing libertarianism and economic collaboration. In 2030 the world is characterised by fairly stable economic growth, although with periods of booms and busts, open markets, rapid scientific 
and technological advances and a fast paced innovation. Relatively quick global economic recovery from the recession of the late 2000s re-established confidence in markets' ability to restructure and respond to challenges without strict regulation. The role of national governance has been declining, while international corporations and city-states, especially in the Far East, have been growing in power. International collaboration is mainly a platform for facilitating global competition and enhancing market efficiency. Alliances are also formed on an ad hoc basis to grasp opportunities of the moment or to solve burning social and environmental problems threatening profits.

The world of 2030 is a world of winners and losers. The gap between rich and poor globally and within the majority of states has widened as individualistic and materialistic values prevail. There is little coordinated global action on many serious environmental problems such as climate change. These environmental problems are left to be dealt with by free-market mechanisms. As a result, environmental problems worsen and environmental impacts, especially from climate change, are a source of increasing devastation around the world. Although growing social unrest, new waves of terrorism and increasing numbers of environmental refugees threaten peace and political stability as well as economic stability, year 2030 is also marked by exciting technological developments in artificial intelligence, bio- and nanotechnologies, the launch of new web technologies and perhaps the first human travel to Mars by Chinese astronauts.

Business and industry are dominated by large global corporations with turnover exceeding the GDP of nation states. Most large corporations have moved away from a hierarchical model towards a distributed multi-polar network model, which gives them much sought agility and flexibility. World-wide "no limits" labour market that allows for free movement of workers between countries, companies and networks fits well with the concept of "agile corporation of 2030". Knowledge workers usually work as freelancers or associates of "talent" networks or agencies. "Jobs for life" are a distant memory of the past, even in a largely privatised and curtailed public sector, while lifelong learning is a must. In most countries people work at least until they are in their 70 s and in some other countries there is no retirement age at all. The business landscape of 2030 is characterised by a whole spectrum of for-profit and non-profit business models, growing number of virtual companies and capabilities networks depending highly on specialised knowledge.

\section{Scenario 2: Green (Equality)}

In this scenario, by 2030, the world has undergone a major transformation. It is a more peaceful, equitable and environmentally sustainable world that maintains relative balance between civic society, governments and business. The period of prolonged economic downturn set in motion by the 2008 financial crisis led to a realisation that uncontrolled exploitation of the natural environment coupled with the exponential growth models could lead to a systemic collapse. A new agreement on climate change signed early in the second decade and the introduction by the G20 countries of a "Better World Programme" shortly thereafter introduced a set of new financial and economic policies aimed at rebalancing society and environment with economic goals. New forms of governance that emerged provided greater access to information and increased involvement of the wider society in decision-making processes. 
Technological innovations in clean-tech, bio- and nano-technologies were directed towards decreasing human impacts on natural systems and improving quality of life for the poorest. The world of science and technology, although developing dynamically, is strictly guided by social needs and ethical concerns. There are still disparities between the rich and poor, however, the gap appears to have narrowed. Quality of life has improved globally, although for many in developed countries it has declined. In 2030 the world is a more peaceful and equitable place, but many believe that the strict rules and regulations that created it have taken away most of their freedom and are burdensome and tiresome for most.

The world of business and industry in 2030 is highly regulated and scrutinised. In many countries, entrepreneurs are frustrated with large amounts of "digital paperwork" and countless compliance procedures that are often in turn slowed down by consensus based decision-making processes. The power of global corporations, although subjected to various global agreements and rules, is only partially curtailed in comparison to the "Orange Scenario". The strictest regulations are in areas of sustainability, Corporate Social Responsibility (CSR) and ethical scrutiny of scientific and technological developments. While care for the natural environment and local societies is now a widely accepted norm, strict regulation of scientific and technological developments is met with growing resistance. Some smaller countries, which did not sign up to international agreements, increasingly attract scientists and engineers to their "science with no limits" heavens. With a global playing field levelled-up, companies move less and so do the people, with the exception of highly skilled workers frequently moving around the globe, while others usually migrate within a region.

\section{Scenario 3: Purple (Fragility)}

In this scenario, the world has been shaped by a socio-political backlash against the forces of change prevailing in 2000s. Long economic stagnation after the near collapse of the global financial system in 2008 combined with lack of consensus and action on global issues, such as climate change and financial market regulations, eroded trust in international institutions and processes. With the rise of protectionism and localisation of markets, in 2030 it is the nation states that have reclaimed their power from global corporations. International cooperation is now limited to the traditional domains of defence, trade and immigration, with regional alliances forming around common interests.

Neither governments nor new technologies solved the most severe social, economic and environmental problems, which are mounting around the globe, intensified by impacts of global warming, rapid, often poorly planned, urbanisation, rising crime levels, terrorism and increasing conflicts around scarce resources. People are turning back to their local communities and cultural roots in search for identity and comfort or escape into a virtual world of entertainment and gaming. Quality of life has decreased for most; however, local communities thrive around the globe increasingly addressing local problems by sharing best practices and solutions through virtual channels.

With the disintegration of the global landscape and curtailment of globalisation processes due to emergence of new political and regulatory barriers many global corporations suffered severely leading to their contraction, fragmentation or in some cases even collapse. The trend towards multi-polar networking observed throughout 
2010s has been reversed and many organisations came back to more hierarchical and vertical structures in response to a need for increased security. Many companies of strategic importance were nationalised to ensure full state control. With shrinking economies the demand for labour decreased and even highly skilled people occasionally have difficulties in securing a job, partly due to stringent restrictions in global labour mobility. It is an employer's market and for most workers temporary contracts are the reality of 2030, with the exception of strategic sectors. Small companies that cannot afford highly skilled staff on their books often use expertise from local and regional sectoral networks, which allows them to have access to knowledge on a project-by-project basis. While overall the world of 2030 under this scenario is challenging, different countries cope differently with these challenges and some are quite successful in securing quite stable economic and social conditions.

\section{Comparison of the Roles and Competences of Engineers under the Three Scenarios}

The engineering profession and consequently engineers' roles and competences will develop differently under the three potential future worlds described above. And, although the total make up of the required skill sets will be diverse, essential engineering competences, such as technical skills, analytical skills, problem solving, communication skills, and IT literacy will continue to be a necessary requirement in each of these worlds. What is likely to be different are the problems and projects these skills will be applied against and emphasis on their different aspects. For example, communication skills will be equally important under all three scenarios, however, in the highly globalised and connected "Orange" world, where engineers work in multinational teams with team members located around the globe the ability to communicate in a concise, clear and unambiguous written manner will be a must. On the other hand, in the fragmented but highly competitive environment of the "Purple" scenario outspoken engineers with capability to communicate, promote and negotiate ideas and solutions as well as to engage effectively with clients are likely to succeed the most. Analytical skills are another example - necessary in all three scenarios - they are likely to be used for solving different types of problems in the "Orange" and "Green" worlds, e.g. improving effectiveness of internet based medical diagnostic instruments in the first one and implementing cradle to cradle approach in the construction industry in the second one. However, in the "Purple" world the analytical skills will need to be embedded in common sense to a much greater degree to make an engineer successful.

When we examine other important skills and competencies that an engineer in 2030 will be required to possess (Table 7.2 provides a full list of capabilities) creativity and innovation, synthesis skills and continuous learning come to the fore. Creativity and innovation and synthesis skills will be essential in the "Green" and "Purple" scenarios, although again for different reasons. For example, in the "Green" scenario these skills will be used to solve complex environmental problems, while in the "Purple" world being creative and innovative will give engineers much higher chances to succeed. 
Another important set of competences, although essential for only one scenario, include professional agility, commercial awareness, team work, flexibility to work in different environments, ability to work independently and practical skills. Professional agility will be an essential competence for engineers working in the "Orange" scenario of high mobility and quickly changing working environments. Commercial awareness will be a must for a majority of engineers in the "Purple" scenario of limited opportunities and greater economic pressures. Team work and flexibility to work in a variety of professional environments will be essential in the "Orange" scenario characterised by high levels of labour mobility between countries, companies, networks and projects. The flexibility to work in different physical and cultural environments will also be required, however, to a lesser extent. In the "Purple" world successful engineers will be required to be able to work independently and be able to utilise their practical skills - 'getting their hands dirty' will be part of their daily jobs. All these skills will be highly desirable in the "Green" world, but not essential.

Engineers operating under the "Orange" and "Purple" scenarios will require somewhat similar sets of essential skills and competences, even if these are required for different reasons, in comparison to the "Green" scenario. There are two key capabilities identified as essential for engineers working in the "Green" world that we perceive only as desired in the other two worlds: having a systemic view and strong social and ethical awareness and responsibility. The "Green" scenario envisions a world attempting to reach a balance between environment, society and economic development. The transformation required to achieve this state will need major changes, including moving away from a fragmented way of thinking about the world towards a systemic perspective. Most engineers will be required to not only think about solutions for a particular project or problem but also to understand how that problem is positioned within a given system, being ecological, transport, social etc., and how the chosen solution will affect other parts of the system or systems. Very high ethical standards and in-depth understanding of CSR will also be a must in a world that places enormous emphasis on ecological and social wellbeing.

Amongst the remaining capabilities that engineers will likely be required to possess are cultural awareness, language skills and understanding of legal frameworks and requirements. Cultural awareness is likely to be highly desired in the "Orange" and "Purple" worlds, again for different reasons. For engineers working in the "Orange" world cultural awareness will be a highly desirable asset, which helps to work more effectively within multinational teams and in different locations around the globe. The growth of importance of local cultures and identities in the "Purple" world will impact also the working environment. For the few engineers able to work in other countries understanding of the culture of their new environment will help them to do better in their jobs. For the same reasons knowledge of languages other than English will also be helpful in this scenario. On the other hand, movement of knowledge and ideas through virtual channels between different locations around the globe will require understanding of the cultural contexts within which they were produced to ensure that they can be successfully implemented in a different location. Finally, although understanding of broader legal frameworks and requirements is a desirable ability for engineers under all scenarios, it seems that it will be particularly important in the "Purple" world, where understanding of legal loopholes will benefit creative and entrepreneurial engineers as well as in the highly regularised environment of the "Green" scenario. 
Table 7.2 Desirability of skills and competences under each scenario $\sqrt{ }$ - desirable; $\sqrt{ } \sqrt{ }$ - highly desirable; $\sqrt{ } \sqrt{ }$ - essential.

\begin{tabular}{|c|c|c|c|}
\hline Skills / Competences & Orange & Green & Purple \\
\hline Technical skills & $\sqrt{ } \sqrt{ }$ & $\sqrt{ } \sqrt{ }$ & $\sqrt{\sqrt{ }}$ \\
\hline Analytical skills & $\sqrt{\sqrt{ } \sqrt{ }}$ & $\sqrt{\sqrt{ }}$ & $\sqrt{\sqrt{ }}$ \\
\hline Communication (written \& oral) & $\sqrt{\sqrt{ }}$ & $\sqrt{\sqrt{ }}$ & $\sqrt{\sqrt{ }}$ \\
\hline Problem solving & $\sqrt{\sqrt{ }}$ & $\sqrt{\sqrt{ }}$ & $\sqrt{\sqrt{ }}$ \\
\hline Computer / IT/ computer tools & $\sqrt{ } \sqrt{ }$ & $\sqrt{ } \sqrt{ }$ & $\sqrt{\sqrt{ }}$ \\
\hline Creativity / Innovation & $\sqrt{ } \sqrt{ }$ & $\sqrt{ } \sqrt{ }$ & $\sqrt{ } \sqrt{ }$ \\
\hline Synthesis skills & $\sqrt{\sqrt{ }}$ & $\sqrt{ } \sqrt{ }$ & $\sqrt{\sqrt{ }}$ \\
\hline The ability for continuous learning & $\sqrt{ } \sqrt{ }$ & $\sqrt{ } \sqrt{ }$ & $\sqrt{ } \sqrt{ }$ \\
\hline Professionally Agile & $\sqrt{ } \sqrt{ }$ & $\sqrt{\sqrt{ }}$ & $\sqrt{\sqrt{ }}$ \\
\hline $\begin{array}{l}\text { Team Work (includes both physical and online } \\
\text { collaboration) }\end{array}$ & $\sqrt{\sqrt{ } \sqrt{ }}$ & $\sqrt{ } \sqrt{ }$ & $\sqrt{\sqrt{ }}$ \\
\hline Commercial awareness & $\sqrt{\sqrt{ }}$ & $\sqrt{\sqrt{ }}$ & $\sqrt{\sqrt{ }}$ \\
\hline Ability to work independently & $\sqrt{ } \sqrt{ }$ & $\sqrt{ } \sqrt{ }$ & $\sqrt{ } \sqrt{ }$ \\
\hline Practical ingenuity & $\sqrt{\sqrt{ }}$ & $\sqrt{\sqrt{ }}$ & $\sqrt{\sqrt{ } \sqrt{ }}$ \\
\hline $\begin{array}{l}\text { Flexible in working in different environments } \\
\text { a) physical } \\
\text { b) cultural } \\
\text { c) professional }\end{array}$ & $\begin{array}{l}\sqrt{ } \\
\sqrt{ } \\
\sqrt{ } \\
\sqrt{ } \sqrt{ }\end{array}$ & $\begin{array}{l}\sqrt{ } \\
\sqrt{ } \\
\sqrt{ } \sqrt{ }\end{array}$ & $\begin{array}{l}\sqrt{ } \\
\sqrt{ } \\
\sqrt{ } \sqrt{ }\end{array}$ \\
\hline Systemic view & $\sqrt{ } \sqrt{ }$ & $\sqrt{ } \sqrt{ }$ & $\sqrt{ }$ \\
\hline Social and ethical awareness and CSR & $\sqrt{ }$ & $\sqrt{ } \sqrt{ }$ & $\sqrt{ }$ \\
\hline Cultural awareness & $\sqrt{ } \sqrt{ }$ & $\sqrt{ }$ & $\sqrt{ } \sqrt{ }$ \\
\hline Understanding of legal requirements & $\sqrt{ }$ & $\sqrt{ } \sqrt{ }$ & $\sqrt{ } \sqrt{ }$ \\
\hline Language skills & $\sqrt{ }$ & $\sqrt{ }$ & $\sqrt{ } \sqrt{ }$ \\
\hline
\end{tabular}

Table 7.2 above attempts to capture the above discussion by describing the desirability of a range of skills that the Engineer of 2030 should possess under each of the three scenarios that we developed. Again noting that engineers practice in many diverse disciplines and perform many diverse roles, even within those disciplines the table should be seen as a generalised summary of desired skills under three different scenarios. Again, it is worth observing the overall consistency of desired skills across the three scenarios and again compared to the earlier survey summarised in Table 7.1, above.

\section{Closing observations}

From the analysis of the skills and competences that engineers will require for different potential worlds of 2030 it is clear that the skills seen as essential today, such as technical and analytical skills, problem solving, IT competences and communication, will continue to be a must in any world that may emerge. However, it is also expected that the importance of other competences, such as creativity and innovation, synthesis skills, ability for continuous learning, professional agility, commercial awareness, ability to work independently and practical ingenuity, will grow 
going into the future. An engineer with these capabilities will have higher chances of success in any future that may emerge. Additionally, there are some new competences that may become important if the world follows a particular path, for example a systemic view and social and ethical awareness become highly desirable capabilities in the "Green" scenario.

A fear has been expressed that while the engineering curriculum must adapt to provide the engineer with a range of key skills over and above their technical engineering skills, it may not be adapting as fast as it needs to. What of the skills that the engineering professor must possess in order to educate the engineering student to succeed in this close, crowded and creative world? Morell and DeBoer summarize the profile of the ideal engineering professor as a technical expert with a savvy and adaptability rooted on actual engineering practice, superior communication skills and recognised as an effective teacher and mentor (2010).

Finally, consider the following rhetorical question: if the engineering school takes students as their raw material and educates them as engineers and sends them out into the world, for whom does the engineering school educate these engineers? Is it for the benefit of the engineers themselves or is it for the organisations or companies in which the engineers will function? Perhaps in an earlier world with the prospect of 'jobs for life' it could be argued that the beneficiary of an engineering education was the company that hired that engineer. In today's close, crowded and creative world we are transitioning from an engineering educational curriculum model that places an emphasis on technical engineering skills, to one that recognises the critical importance of a range of other key skills. Therefore, and perhaps it might appear as self-evident, it is becoming increasingly clear that the beneficiary of an engineering education must first be the engineer. If the engineer can, through their engineering curriculum, acquire and develop the other necessary non-technical skills identified in this chapter, then it will also benefit the company that hires the engineer. And that should also be better for society.

\section{References}

ABET (2010) Criteria for Accrediting Engineering Programs. Baltimore: ABET.

Bowser, J. (2011) Strategic Co-opetition: The Value of Relationships in the networked economy. Available online: http://www935.ibm.com/services/uk/index.wss/multipage/igs/ibvstudy/a1008082/1?cntxt=a1006870. Accessed on 29th April 2011.

Drucker, P. (2001) The next society. The Economist. $1^{\text {st }}$ November 2001. Available online: http://www.economist.com/node/770819. Accessed on 29th April 2011.

EC (2006) The Accreditation of Higher Education Programmes: UK Standard for Professional Engineering Competence. Published by Engineering Council.

EI (2007) Accreditation Criteria for Engineering Education Programmes. Engineers Ireland, March 2007.

Friedman, T. L. (2006) The World is Flat: A Brief History of the Twenty-First Century. New York: Farrar, Straus and Giroux.

IOT (2011) Level 8 Engineering Graduate Research Study. DIT and Institutes of Technology, June 2011.

Krawczyk, E. (2010) Futures Thinking in City Planning Processes: The Case of Dublin. Saarbrücken: Lambert Academic Publishing.

Krawczyk, E., Ronchetti, P. (2009) Dublin at the Crossroads: Exploring the Future of the Dublin City Region. Dublin: TFA. Available online: http://www.thefuturesacademy.ie/node/117.

Morell, L., DeBoer, J. (2010) The Engineering Professor of 2020: the Forgotten Variable. ASEE Annual Conference, June 2010. 
NAE (2004) The Engineer of 2020: Visions of Engineering in the New Century. Washington DC: The National Academies Press.

Ratcliffe, J. (2005) Imagineering Ireland: Future Scenarios for 2030. Dublin: TFA.

Ratcliffe, J. (2009) Navigating Unchartered Waters: The Use of Strategic Foresight and Scenarios in Creating Better Built Environment. Presentation. Available online: http://thefuturesacademy.ie/node/160.

Spencer, B. (2002) Introduction to the Special Issue on Agent Technologies for Electronic Commerce. NRC Publications Archive. Available online: http://nparc.cisti-icist.nrccnrc.gc.ca/npsi/ctrl?action=shwart\&index $=$ an\&req=5763779\&lang=en. Accessed on $26^{\text {th }}$ April 2011.

TFA (2008) Twice the Size? Imagineering the Future of Irish Gateways. Dublin: TFA. Available online: http://www.thefuturesacademy.ie/node/63.

Wheeler, S. (2001) Information and Communication Technologies and the Changing Role of the Teacher. Learning, Media and Technology, 26: 1, 7-17 